\title{
PENERAPAN MODEL PENYEMBUHAN DENGAN REGRESI COX HAZARD PROPORSIONAL PADA PENYAKIT KANKER KOLOREKTAL
}

\author{
Wirna Arifitriana ${ }^{1)}$, Danardono ${ }^{2)}$ \\ 1) Pendidikan Matematika, FKIP Universitas Graha Nusantara \\ ${ }^{2)}$ Departemen Matematika, FMIPA Universitas Gadjah Mada \\ email: wirnaariv3ana@gmail.com
}

\begin{abstract}
Survival analysis is a statistical technique used to analyze the data, aims to determine the variables that affect the outcome of a beginning to end the incident. One model of survival is a cure model is useful for estimating the proportion of patients who recover and the probability of survival of patients who did not recover until the deadline given. Analysis on Cox regression cure model Hazard Proportional with Maximum Likelihood Estimates and Algorithm Expectation Maximization (EM).
\end{abstract}

Keywords: Cox Proportional Hazard Cure Model, MLE, EM algorithm, likelihood ratio test, Wald test.

\begin{abstract}
Abstrak
Analisis survival merupakan tehnik statistika yang digunakan untuk menganalisa data, bertujuan untuk mengetahui hasil dari variabel yang mempengaruhi suatu awal sampai akhir kejadian. Salah satu model survival yaitu model penyembuhan (cure model) yang berguna untuk mengestimasi proporsi pasien yang sembuh dan probabilitas survival pasien yang tak sembuh sampai pada batas waktu yang diberikan. Analisis pada model penyembuhan dengan regresi Cox Hazard Proportional dengan estimasi Likelihood Maximum dan Algoritma Expectation Maximization (EM).
\end{abstract}

Kata kunci: Cox Proportional Hazard, Cure Model, MLE, algoritma EM, uji rasio likelihood, uji Wald.

\section{PENDAHULUAN}

Salah satu analisis regresi yang terkenal untuk menganalisa data survival adalah regresi Cox. Regresi Cox termasuk ke dalam metode semiparametrik yang mana fungsi baseline hazard mengikuti model nonparametrik sedangkan variabel - variabel independennya mengikuti model parametrik. Tujuan dari metode regresi Cox adalah untuk mengetahui hubungan antara waktu survival dengan variabel-variabel yang diduga mempengaruhi waktu survival (Cox, 1972).

Analisis survival merupakan teknik statistik yang digunakan untuk menganalisis data yang bertujuan untuk mengetahui hasil dari variabel yang mempengaruhi suatu awal kejadian sampai akhir kejadian. Dalam analisis survival, ada istilah failure (meskipun peristiwa sebenarnya mungkin saja sukses) yaitu suatu kejadian dimana tercatatnya kejadian yang diinginkan. 
EKSAKTA : Jurnal Penelitian dan Pembelajaran MIPA

Volume 4 Nomor 1 Tahun 2019

Regresi Cox memiliki variabel dependen yaitu waktu survival dan variabel independen yaitu variabel yang diduga mempengaruhi waktu survival. Cure models 
merupakan model survival yang dikembangkan untuk estimasi proporsi pasien yang sembuh (cure) dalam studi klinik. Model ini selain digunakan untuk mengestimasi proporsi pasien yang sembuh juga digunakan untuk mengestimasi probabilitas survival pasien yang tak sembuh sampai pada batas waktu yang diberikan.

Model mixture dikatakan model (cure) mixture parametrik jika menggunakan distribusi probabilitas standar seperti distribusi eksponensial, Weibull, Gompertz, dan generalized gamma. Diskusi tentang model mixture parametrik beberapa dapat di lihat pada Boag (1949), Jones dkk (1981), Farewell (1982, 1986).

\section{Estimator Proporsional Hazard Cox Cure Model}

Misalkan $\mathrm{Y}$ adalah indikator dari individu mencapai suatu event $(Y=1)$ atau tidak pernah $(Y=0)$ dengan $p=\operatorname{Pr}(Y=1)$. Misalkan $\mathrm{T}$ menunjukkan waktu untuk suatu kejadian event, didefinisikan hanya ketika $\mathrm{Y}=1$, dengan kepadatan $f(t \mid Y=1)$ dan fungsi survival $S(t \mid Y=1)$. Untuk individu tersensor, Y tidak diamati. Fungsi Margin survival dari T adalah $S(t)=(1-p)+p S(t \mid Y=1)$ untuk $t<\infty$. Perhatikan bahwa $S(t) \rightarrow 1-p$ sebagai $t \rightarrow \infty$. Kita asumsikan independent, noninformatif, model tersensor acak dan tersensor statistik independent dari Y.

Farewell (1982) menggunakan model regresi logistik untuk kejadian $p(x)=$ $\operatorname{Pr}(Y=1 ; x)=\exp \left(x^{\prime} b\right) /\left(1+\exp \left(x^{\prime} b\right)\right)$, dimana kovarian dari $\mathrm{x}$ vektor termasuk intercept dan model survival parametrik untuk $S(t \mid Y=1)$. Kuk dan Chen (1992) menggeneralisasi ini dengan menggunakan model Cox Proportional Hazard dengan fungsi hazard $\lambda(t \mid Y=1 ; z)=\lambda_{0}(t \mid Y=1) \exp \left(x^{\prime} \beta\right)$, dimana $\mathrm{z}$ adalah vektor kovarian intercept yang lain dan $\lambda_{0}(t \mid Y=1)$ adalah fungsi dasar hazard bersyarat. Melalui $\mathrm{b}$ dan $\beta$, model tersebut mampu memisahkan efek kovariat pada kejadian dan latensi dan, dalam arti bahwa, menyediakan kelas yang fleksibel dari model ketika terdapat keyakinan apriori dalam kelompok yang tidak rentan. Untuk model Kuk and Chen, fungsi hazard kumulatif bersyarat adalah $\Lambda(t \mid Y=1 ; z)=$ $\Lambda_{0}(t \mid Y=1) \exp \left(z^{\prime} \beta\right), \quad$ dimana $\quad \Lambda_{0}(t \mid Y=1 ; z)=\int_{0}^{t} \lambda_{0}(u \mid Y=1) d u$. Fungsi survival bersyarat adalah $S(t \mid Y=1 ; z)=S_{0}(t \mid Y=1)^{\exp \left(z^{\prime} \beta\right)}$ dimana $S_{0}(t \mid Y=1)$ adalah fungsi dasar survival bersyarat.

Model standar Proportional Hazard adalah sebuah kasus khusus dari model Cure Proportional Hazard dimana $p(x)=1$ untuk setiap $x$, model Cure Proportional Hazard adalah kasus khusus dari model kelemahan perkalian, dimana bahaya untuk individual, kondisional pada $Y$, dapat dituliskan $\lambda(t \mid Y ; z)=Y \lambda(t \mid Y=1 ; z)$. Sebagai sebuah variabel kelemahan, $Y$ tidak sepenuhnya teramati sejak individu dianggap sebagai $Y=1$ jika suatu kejadian teramati.

\section{Maksimum likelihood estimation}

Data yang diobservasi menunjukkan nilai $i$ oleh $\left(t_{i}, \delta_{i}, z_{i}\right), i=1, \ldots, n$, dimana $t_{i}$ adalah kejadian yang diamati atau waktu tersensor, $\delta_{i}=1$ jika $t_{i}$ tidak tersensor dan $\delta_{i}=0$ untuk yang lain, dan $z_{i}$ adalah suatu vektor kovarian. Untuk faktor keamanan, kita misalkan $x_{i}=\left(1, z_{i}^{\prime}\right)$, meskipun kovariat pada $x_{i}$ dan $z_{i}$ tidak harus identik. Nilai $\mathrm{k}$ menunjukkan nilai waktu kejadian yang berbeda dimana $t_{(i)}<\cdots<t_{(k)}$. Hal ini menunjukkan bahwa, jika $\delta_{i}=1, y_{i}=1$ dan, jika $\delta_{i}=0$, $y_{i}$ tidak teramati, dimana $y_{i}$ adalah nilai yang diambil dari variabel acak $Y_{i}$. Kontribusi kemungkinan dari $i$ adalah $p_{i} f\left(t_{i} \mid Y=1 ; z_{i}\right)$ untuk $\delta_{i}=1$ dan $(1-$ 
$\left.p_{i}\right)+p_{i} S\left(t_{i} \mid Y=1 ; z_{i}\right) \quad$ untuk $\quad \delta_{i}=0 \quad$ dimana $\quad p_{i}=\operatorname{pr}\left(Y=1 ; x_{i}\right) . \quad$ Untuk Proportional Hazard Cure Model, kemungkinan teramati secara keseluruhan adalah :

$$
\begin{aligned}
L\left(b, \beta, \Lambda_{0}\right)= & \prod_{i=1}^{n}\left\{p_{i} \Lambda_{0}\left(t_{i} \mid Y=1\right) e^{z_{i}^{\prime} \beta} e^{-\Lambda_{0}\left(t_{i} \mid Y=1\right) \exp \left(z_{i}^{\prime} \beta\right)}\right\}^{\delta_{i}} \\
& \times\left\{\left(1-p_{i}\right)+p_{i} e^{-\Lambda_{0}\left(t_{i} \mid Y=1\right) \exp \left(z_{i}^{\prime} \beta\right)}\right\}^{1-\delta_{i}}
\end{aligned}
$$

\section{Algoritma Expectation Maximization}

Algoritma EM merupakan metode optimisasi iteratif untuk mendapatkan estimasi likelihood maksimum yang berguna dalam permasalahan data hilang atau tidak lengkap. Data keseluruhan ditunjukkan oleh $\left(t_{i}, \delta_{i}, z_{i}, y_{i}\right), i=1, \ldots, n$ termasuk data yang diamati dan $y_{i}^{\prime} s$ yang tidak diamati. Keseluruhan data dari full hazard adalah :

$$
\begin{aligned}
L_{C}\left(b, \beta, \Lambda_{0} ; y\right) & =\prod_{i=1}^{n} p_{i}^{y_{i}}\left(1-p_{i}\right)^{1-y_{i}} \prod_{i=1}^{n}\left\{\lambda_{0}\left(t_{i} \mid Y=1\right) e^{z_{i}^{\prime} \beta}\right\}^{\delta_{i} y_{i}} \times e^{-y_{i} \Lambda_{0}\left(t_{i} \mid Y=1\right) \exp \left(z_{i}^{\prime} \beta\right)} \\
& =L_{1}(b ; y) L_{2}\left(\beta, \Lambda_{0} ; y\right)
\end{aligned}
$$

dimana $y$ adalah vektor dari nilai $y_{i}$. Faktor hazard merupakan logistik dan komponen Proportional Hazard. Kita menggunakan notasi $L$ untuk hazard dan $l$ untuk log-likehood.

Langkah $E$ memperkirakan $l_{C}\left(b, \beta, \Lambda_{0} ; y\right)$ sehubungan dengan distribusi $y_{i}{ }^{\prime} s$ teramati, diberikan nilai-nilai parameter dan data $O$ yang ter amati, dimana $O=\left\{y_{i}^{\prime}\right.$ s teramati, $\left.\left(t_{i}, \delta_{i}, z_{i}, y_{i}\right), i=1, \ldots, n\right\}$. Perhatikan bahwa, untuk kasus tersensor, yang $y_{i}{ }^{\prime} s$ adalah linear dalam data lengkap log-likehood sehingga kita hanya perlu menghitung

$$
\begin{aligned}
\pi_{i}^{(m)}= & E\left(Y_{i} \mid \theta^{(m)}, O\right) \\
= & \operatorname{pr}\left(Y_{i}=1 \mid T_{i}>t_{i}, \delta_{i}=0, z_{i} ; \theta^{(m)}\right) \\
= & \operatorname{pr}\left(Y_{i}=1 ; b\right) S_{0}\left(t_{i} \mid Y=1\right)^{\exp \left(z_{l}^{\prime} \beta\right)} \div\left[1-\operatorname{pr}\left(Y_{i}=1 ; b\right)+\right. \\
& \left.\operatorname{pr}\left(Y_{i}=1 ; b\right) S_{0}\left(t_{i} \mid Y=1\right)^{\exp \left(z_{l}^{\prime} \beta\right)}\right]\left.\right|_{\theta=\theta^{(m)}}
\end{aligned}
$$

untuk kasus tersensor, dimana $\theta=\left(b, \beta, \Lambda_{0}\right), \theta^{(m)}$ menunjukkan nilai parameter yang ada pada iterasi mth, dan $S_{0}\left(t_{i} \mid Y=1\right)=\exp \left\{-\Lambda_{0}\left(t_{i} \mid Y=1\right)\right\}$. Untuk $i$ tidak tersensor, $E\left(Y_{i} \mid \theta^{(m)}, O\right)=y_{i}=1$. Dengan demikian, langkah E menggantikan $y_{i}{ }^{\prime} s$ dengan $w_{i}{ }^{(m)}$, yang sama dengan satu jika $i$ tidak tersensor dan sama dengan $\pi_{i}{ }^{(m)}$ jika $i$ tersensor. Perkiraan dari loglikehood oleh $\tilde{l}_{C}\left(b, \beta, \Lambda_{0} ; w^{(m)}\right)=\tilde{l}_{1}\left(b ; w^{(m)}\right)+$ $\tilde{l}_{2}\left(\beta, \Lambda_{0} ; w^{(m)}\right)$, dimana $w^{(m)}=\left\{w_{i}^{(m)}: i=1, \ldots, n\right\}$.

Langkah M melibatkan algoritma maksimum dari $\tilde{l}_{C}$ berdasarkan $b$ dan $\beta$ dan fungsi $\Lambda_{0}$, diberikan $w^{(m)}$. Untuk menghadapi fungsi gangguan $\Lambda_{0}(t \mid Y=1)$ atau $S_{0}(t \mid Y=1)$, kita menambahkan tahap penyempurnaan tambahan pada langkah $\mathrm{M}$ menggunakan tehnik hazard. Dua metode dari Cox Proporsional Hazard dapat diperluas : estimator tipe Breslow untuk $\Lambda_{0}\left(t_{i} \mid Y=1\right)$ dan estimator batasan untuk $S_{0}\left(t_{i} \mid Y=1\right)$.

\section{Aspek Komputasi}


Taylor (1995) mengemukakan bahwa kendala $S_{0}\left(t_{(k)} \mid Y=1\right)=0$ adalah bentuk khusus dari Proportional Hazard mixture model dengan $\beta=0$. Kendala terjadi secara otomatis ketika bobot $w_{l}^{(m)}$ untuk pengamatan tersensor setelah $t_{(k)}$ menjadi nol pada langkah $\mathrm{E}$, pada dasarnya mengklasifikasikan bahwa itu tidak rentan. Solusi dengan kendala ini memiliki sifat statistik yang lebih baik dan konvergen lebih cepat dari MLE yang tidak terbatas.

Maximization algoritma dalam langkah M. Dalam langkah $M$, kita menggunakan prosedur Newton-Raphson (NR) untuk memaksimalkan $\tilde{l}_{1}\left(\beta ; w^{(m)}\right)$ untuk mendapatkan $\hat{b}$. Simulasi NR pada $(\beta, \alpha)$ menggunakan $\tilde{l}_{1}\left(\beta, \alpha ; w^{(m)}\right)$, bagaimanapun sensitif terhadap nilai awal dam akan mudah gagal untuk konvergen. Metode yang ditemukan untuk menjadi efisien adalah dua langkah dari NR yang disarankan oleh Prentice dan Gloeckler (1978) dalam model Proportional Hazard dalam memperbaharui dari $\beta$ dan $\alpha$ yang diperoleh secara bergantian. Kita menggunakan parameterisasi $\lambda_{i}=-\log \alpha_{i}$. Dari pengalaman bahwa algoritma di atas tidak didapatkan. Data yang diamati dari likelihood meningkat dari setiap iterasi EM., dan nilai awal berbeda memberikan mode yang sama. Hal ini dimungkinkan untuk estimasi $b$ dan/atau $\beta$ menjadi tak terbatas. Hal ini sangat jarang terjadi dan hanya jika ukuran sampel kecil dan ada jumlah yang sangat kecil dari setiap kejadian atau survivor.

\section{Standard Error Dan Inferensi}

Diperoleh perkiraan dari variansi asymptotik dari $(\widehat{b}, \hat{\beta})$ berdasarkan kebalikan dari informasi matriks $I(b, \beta, \lambda)$ lengkap teramati. Perhitungan didasarkan pada likelihood yang teramati penuh yang diparameterkan berdasarkan model Proportional Hazard diskrit

$$
\begin{aligned}
L(b, \beta, \lambda)=\prod_{i=0}^{k} & {\left[\prod_{l \in D_{i}}\left\{1-e^{-\lambda_{i} \exp \left(z_{l}^{\prime} \beta\right)}\right\} \times \exp \left(-\sum_{j: t_{(j)} \leq t_{(i-1)}} \lambda_{j} e^{z_{l}^{\prime} \beta}\right)\right] } \\
\times & {\left[\prod_{l \in C_{i}}\left\{(1-p)+p_{l} \exp \left(\sum_{j: t_{(j)} \leq t_{(i)}} \lambda_{j} e^{z_{l}^{\prime} \beta}\right)\right\}\right] }
\end{aligned}
$$

\section{STUDI KASUS \\ Deskripsi Data}

Data yang digunakan dalam penelitian ini adalah data sekunder yang diperoleh dari Karya Ilmiah Paripurna fakultas Kedokteran UGM pada periode Januari sampai dengan Desember 1999. Rahmad (2006) melakukan penelitian terhadap 78 pasien penderita kanker kolorektal dan didapatkan sebanyak 43 pasien masih bertahan hidup dan 35 pasien meninggal. Mayoritas penderita adalah laki-laki sebanyak 50 pasien dan 28 pasien perempuan.

Tabel 1. Data pasien penyakit kanker kolorektal

\begin{tabular}{|c|l|c|c|}
\hline No & \multicolumn{1}{|c|}{ Jenis Kelamin } & Hidup & Meninggal \\
\hline 1. & Pasien Laki-laki & 30 & 20 \\
\hline 2. & Pasien Perempuan & 13 & 15 \\
\hline \multicolumn{2}{r}{ Pasien total } & $\mathbf{4 3}$ & $\mathbf{3 5}$ \\
\hline
\end{tabular}


Berikut ini adalah variabel - variabel yang digunakan yaitu :

a. Variabel Dependen :

b. Variabel Independen

1. Jenis kelamin pasien ( $1=$ Laki-laki, $0=$ Perempuan $)$

2. Umur Pasien

3. Stadium Dukes

Stadium tumor menurut Dukes modifikasi Turnbull ditetapkan dari laporan operasi meliputi Dukes A, B, C dan D

4. Jenis Operasi ( $1=$ Elektif, $0=$ Emergency)

5. Terapi

\section{ANALISIS DATA}

\section{Model Cure}

Secara umum cure model dinyatakan sebagai berikut:

$$
\pi(z)=\frac{\exp (b z)}{1+\exp (b z)}
$$

Tabel 2. Estimasi dengan nboot $=10$, nboot $=20$ dan nboot $=30$

\begin{tabular}{|l|c|c|c|}
\hline & SE $(\mathbf{n b o o t}=\mathbf{1 0})$ & SE $(\mathbf{n b o o t}=\mathbf{2 0})$ & SE $(\mathbf{n b o o t}=\mathbf{3 0})$ \\
\hline Cure probability model & 0,0010820292 & 0,0009876189 & 3,293356 \\
JK & 0,0002082207 & 0,0007327752 & 2,077682 \\
UMUR & 5,7661580736 & 6,6905967834 & 8,096843 \\
J.OPERASI & 0,9953950148 & 0,6301596925 & 1,641129 \\
T.LKP & 7,3346243716 & 6,8305137339 & 8,138435 \\
T.TLKP & 4,1275725792 & 8,7698624813 & 10,616308 \\
STADIUM2 & 2,8276805922 & 8,3719106121 & 10,628397 \\
STADIUM3 & & & \\
\hline Failure time distribution model & 0,5153363 & 0,5174826 & 0,7532487 \\
JK & 0,4135528 & 0,1867372 & 0,2849693 \\
UMUR & 0,7392011 & 0,6681020 & 0,7008350 \\
J.OPERASI & 0,8234033 & 1,0749470 & 1,5002460 \\
T.LKP & 1,4814685 & 1,1680694 & 1,6234455 \\
T.TLKP & 0,7252889 & 0,4686885 & 0,6414544 \\
STADIUM2 & 0,8838928 & 0,7041828 & 1,2673194 \\
STADIUM3 & \multicolumn{3}{|}{} \\
\hline
\end{tabular}

Dari ketiga nboot pada tabel 2 dapat kita lihat bahwa nboot $=10$ memiliki 4 nilai standar error yang kecil dibandingkan nboot yang lain.

Tabel 3. Estimasi parameter model Cure

\begin{tabular}{|c|c|c|}
\hline Variabel & Estimasi & P-Value \\
\hline Jenis Kelamin & $-1,388927$ & $0,000000 \mathrm{e}+00$ \\
\hline Umur & 1,719028 & $0,000000 \mathrm{e}+00$ \\
\hline Jenis Operasi & 10,781749 & $6,150711 \mathrm{e}-02$ \\
\hline T. Lengkap & 24,356449 & $0,000000 \mathrm{e}+00$ \\
\hline T. Tidak Lengkap & 5,428664 & $4,592138 \mathrm{e}-01$ \\
\hline Stadium2 & 1,121343 & $7,858748 \mathrm{e}-01$ \\
\hline Stadium3 & $-21,680278$ & $1,754152 \mathrm{e}-14$ \\
\hline
\end{tabular}


Berdasarkan hasil estimasi yang di tunjukkan pada tabel 3 variabel jenis kelamin, umur, terapi lengkap dan stadium3 atau stadium D berpengaruh secara signifikan terhadap model cure. Hasil ini dapat diinterpretasikan sebagai berikut:

1. Seorang pasien berjenis kelamin laki-laki maka akan menurunkan banyak pasien yang hidup terhadap penyakit kanker kolorektal sebesar $\exp (-1,388927)=0,2493$. Namun untuk seorang pasien berjenis kelamin perempuan maka akan menurunkan banyak pasien yang hidup terhadap penyakit kanker kolorektal sebanyak seorang pasien. Jadi pasien dengan jenis kelamin perempuan lebih beresiko terjangkit kanker kolorektal.

2. Setiap penambahan umur seorang pasien maka akan menaikkan banyak pasien yang hidup terhadap penyakit kanker kolorektal sebesar $\exp (1,719028)=5,579$ dengan kata lain semakin bertambah umur seorang pasien maka akan menambah 6 pasien yang hidup terhadap penyakit kanker kolorektal.

3. Seorang pasien mengikuti terapi lengkap maka akan menambah banyak pasien yang hidup terhadap penyakit kanker kolorektal sebesar $\exp (24,356449)=3,7833 \times 10^{10}$. Namun untuk setiap seorang pasien yang tidak mengikuti terapi lengkap maka akan menaikkan banyak pasien yang hidup terhadap penyakit kanker kolorektal sebanyak seorang pasien. Jadi semakin banyak pasien yang mengikuti terapi lengkap maka akan menambah banyak pasien yang hidup terhadap penyakit kanker kolorektal.

4. Seorang pasien yang dinyatakan stadium 3 maka akan menurunkan banyak pasien yang hidup terhadap penyakit kanker kolorektal sebesar exp($21,680278)=3,840 \times 10^{-10}$. Namun untuk setiap seorang pasien yang tidak dinyatakan stadium 3 maka akan menurunkan banyak pasien yang hidup terhadap penyakit kanker kolorektal sebanyak seorang pasien.

\section{KESIMPULAN}

Berdasarkan pembahasan dan studi kasus pada bab sebelumnya, maka dapat ditarik kesimpulan sebagai berikut:

Secara umum cure model dinyatakan sebagai berikut:

$$
\pi(z)=\frac{\exp (b z)}{1+\exp (b z)}
$$

Hasil estimasi parameter untuk cure model menghasilkan persamaan dugaan sebagai berikut:

$$
\pi(x)=\frac{\exp \left(-1,388927 X_{J K}+1,719028 X_{u m u r}+10,781749 X_{J . o p}+24,356449 X_{T . L k p}\right.}{\left.+5,428664 X_{T . T L k p}+1,121343 X_{S t .2}-21,680278 X_{S t .3}\right)}
$$

Variabel prediktor yang berpengaruh signifikan terhadap banyak pasien yang hidup pada penyakit kanker kolorektal pada model Cure yaitu jenis kelamin, Umur, terapi lengkap dan jenis stadium 3 sedangkan variabel prediktor lainnya yaitu jenis operasi, terapi tidak lengkap dan jenis stadium 2 tidak berpengaruh secara signifikan terhadap banyak pasien yang hidup terhadap penyakit kanker kolorektal.

\section{REFERENSI}

Boag, J.W. 1949. Journal of the Royal Statistical Society. Series B ( Methodological) Vol. 11, No. 1, pp. 15-53 
Cox, D.R., 1972, Regression models and life tables (with Discussion), Journal of The Royal Statistical Society B 34, 187 - 220.

Danardono, 2012, Analisis Data Survival, Diktat Kuliah, UGM, Yogyakarta.

Farewell, V.T.1982. The use ofmixture models for analysis of survival data with long-term survivors. Biometrics 38, 1041 - 1046.

Farewell, V. T., 1986. The use of mixture models for the analysis: Are they worth the risk? Canadian Journal of Statistics 14, 257 - 262

Jones, D.R., Powles, R.L., Machin, D., and Sylvester, R.J. 1981. On Estimating the proportion of cured patients in clinical studies. Biometrie-Praximetrie 21, 1-11.

Kuk, A. Y. C. and Chen, C. H., 1992. A mixture model combining logistic regression with proportional hazards regression. Biometrika 79, 531-541.

Taylor, J.M.G. 1995. Semi-parametric Estimation in Failure-Time Mixture Models. Biometrics. Vol.51: 899-907 